\title{
UM MODELO PARA AVALIAÇÃO DO POTENCIAL ESTRATÉGICO DE PROJETOS DE P\&D DE INOVAÇÃO TECNOLÓGICA
}

\section{A MODEL FOR EVALUATING THE POTENTIAL OF STRATEGIC R\&D PROJECTS FOR TECHNOLOGICAL INNOVATION}

\author{
Flavio Lucas da Rosa*E-mail: flaviotaq@gmail.com \\ Carlos Fernando Jung* E-mail: carlosfernandojung@gmail.com \\ Paulo Roberto von Mengden* E-mail: pmengden@gmail.com \\ ${ }^{*}$ Faculdades Integradas de Taquara,Taquara,RS
}

\begin{abstract}
Resumo: Este artigo apresenta um modelo para avaliação do potencial estratégico de projetos de Pesquisa e Desenvolvimento (P\&D) de inovação tecnológica aplicado ao Programa de Apoio aos Polos de Inovação Tecnológica do Estado do Rio Grande do Sul. Através de um estudo bibliográfico documental foram examinados modelos para seleção e priorização de projetos, os Fatores Críticos de Sucesso (FCS), as diretrizes do Programa de Polos e métodos de tratamento e processamento de dados. Foi proposta uma plataforma para aquisição, tratamento e saída de dados, juntamente com um conjunto de indicadores capazes de estabelecer uma pontuação estratégica que permite a seleção e classificação de projetos. O modelo além de selecionar e classificar projetos de P\&D facilita a avaliação dos pontos fortes e fracos dos projetos analisados.
\end{abstract}

Palavras-chave: Seleção. Projetos. P\&D. Priorização.

Abstract: This paper presents a model for assessing the strategic potential of Research \& Development (R\&D) projects in technological innovation applied to Program of Technology Innovation Centers of the State of Rio Grande do Sul, Brazil Through a bibliographical study, were analyzed models of selection and prioritization of projects, the Critical Success Factor (CSF), guidelines of the Program and treatment methods and data processing. We propose a platform for acquisition, processing and data output, together with a set of indicators to establish a strategic score that allows the selection and ranking of projects. The model proposed in addition to select and rank projects in $\mathrm{R}$ \&D facilitates the evaluation of strengths and weaknesses of the analyzed projects.

Keywords: Selection. Design. R \& D. Prioritization.

\section{INTRODUÇÃO}

O Governo do Estado do Rio Grande do Sul possui um programa de incentivo aos Polos de Inovação Tecnológica destinado a financiar projetos de pesquisa aplicada elaborados a partir de demandas regionais (SCT, 2010a). Anualmente este Programa lança editais para financiamento baseados em temas estratégicos. Jung et al. (2008a) referem que os projetos propostos pelos pesquisadores dos Polos são 
avaliados inicialmente pelos gestores dos Polos quanto a viabilidade econômica, científica, tecnológica e, principalmente, se a proposta enquadra-se nas linhas de pesquisa do respectivo Polo e edital. Os projetos selecionados pelos gestores são novamente selecionados, classificados e aprovados pela SCIT/RS (Secretaria da Ciência, Inovação e Desenvolvimento Tecnológico do RS) que utiliza os mesmos critérios adotados pelos gestores dos Polos (JUNG et al., 2008a).

Este artigo apresenta os resultados de uma pesquisa que teve por finalidade desenvolver um modelo para seleção e classificação de projetos de pesquisa e desenvolvimento (P\&D). Este modelo destina-se a avaliar o potencial estratégico de projetos a serem submetidos ao Programa de Polos de Inovação Tecnológica do RS. Inicialmente foi realizado um estudo bibliográfico e documental sobre modelos de seleção e priorização de projetos, Fatores Críticos de Sucesso, diretrizes do Programa de Polos e métodos para processamento de dados e informações. Este estudo permitiu o desenvolvimento de um modelo, que para ser avaliado foi posteriormente aplicado em uma amostra. A análise dos resultados permitiu otimizar o modelo proposto para a seleção e classificação de projetos. O restante deste artigo está organizado da seguinte forma: a seção 2 apresenta o referencial sobre o tema, a seção 3 descreve o estudo aplicado, a seção 4 apresenta a verificação do modelo e a seção 5 traz as conclusões do estudo.

\section{REVISÃO TEÓRICA}

\subsection{Modelos para seleção de projetos}

Ao examinar as estratégias das organizações na execução de diversos projetos, Cooper e Edgett (2008) afirmam que o portfólio de projetos representa na prática a visão estratégica destas. Já Rozenfeld et al. (2006) afirmam que cada novo projeto deve ser tratado como um novo negócio pela organização, incluindo-o na sua estratégia empresarial. Para Barros, Silva e Mello (2010) o processo de seleção de portfólio de projetos consiste em construir uma carteira de projeto a partir de uma série de alternativas, selecionando aquelas que melhor se adéquam a critérios diversos preestabelecidos pela organização.

Revista Produção Online, Florianópolis, SC, v.13, n. 3, p. 1167-1196, jul./set. 2013. 
Nesta mesma linha o Project Management Institute - PMI (2008) ressalta a necessidade de uma priorização estratégica dos projetos em processos de avaliação, pois cada um está disputando os recursos gerais da organização. Por sua vez, Castro e Carvalho (2010), indicam a existência de uma grande quantidade de modelos para seleção e classificação de projetos, no entanto, salientam a reduzida aplicação destes pelas instituições, o que pode fragilizar suas próprias estratégias de ação. Corroborando, Paula, Amaral e Rozenfeld (2007) afirmam que a gestão de projetos é uma atividade que depende da tomada constante de decisões e a qualidade do resultado pode depender do uso de técnicas de simulação ou análise.

Para Magalhães (2003) em muitas organizações os projetos contam com forte apoio interno, mesmo não tendo nenhuma relação com a estratégia da organização, sendo simplesmente "sacred cows" (vacas sagradas). Isto indica que determinados projetos são aprovados apenas levando em conta a reputação ou posição de seu autor sem qualquer análise estratégica. A falta de um método com critérios para determinar o potencial de um projeto pode resultar em insucesso (BITMAN e SHARIF, 2008). Neste caso, Silva, Hartman e Reis (2008) referem que muitas empresas que produziam produtos ou ofereciam serviços de qualidade já pereceram nos últimos anos devido a falta de inovação percebida pelos seus consumidores.

Demandas são as necessidades e restrições identificadas tanto no âmbito organizacional como no mercado. É através delas que as empresas podem estabelecer os objetivos de um projeto e identificar as características que geram maior valor (PEGORARO, SAURIN e PAULA, 2011). Assim, torna-se evidente a necessidade das organizações em encontrar formas de priorizar seus projetos com base nos possíveis riscos, condições de financiamento e princípios do plano estratégico da organização (PMI, 2008). O desenvolvimento de métodos capazes de selecionar e priorizar os projetos mais atrativos para o mercado e mais adequados ao plano estratégico da organização poderá contribuir para o sucesso destes (CHAO e KAVADIAS, 2008).

Magalhães (2003) afirma que os patrimônios intangíveis, tais como marca, reputação, imagem social e capacidade de adaptação às mudanças tecnológicas, representam uma porção em ascensão no valor de uma organização. Este autor diz 
que existe uma demanda por indicadores que possam balizar estes patrimônios intangíveis, diluindo o peso dos indicadores financeiros sobre a escolha de projetos, valorando o seu potencial estratégico para a organização.

Um projeto é um esforço temporário que busca um resultado exclusivo, e que frequentemente é utilizado como meio de atingir metas do plano estratégico das organizações (PMI, 2008). Já Jung et al. (2009a) e Bell (2008) afirmam que projetos são compostos de etapas sistematicamente ordenadas, com finalidade de detalhar um conjunto de ações a serem executadas para suprir uma necessidade.

A OCDE (2007b) afirma que a pesquisa e desenvolvimento (P\&D) abrange três tipos de pesquisa: (i) Pesquisa básica, definida como trabalhos experimentais ou teóricos destinados a obter novos conhecimentos, sem ter em vista qualquer aplicação específica (OCDE, 2007b); (ii) pesquisa aplicada, que são trabalhos originais realizados para adquirir novos conhecimentos, mas com um objetivo prático específico (OCDE, 2007b); e (iii) Desenvolvimento experimental, apresentados como trabalhos sistemáticos baseados nos conhecimentos existentes obtidos pela investigação e/ou pela experiência prática (OCDE, 2007b).

A tecnologia é a aplicação do conhecimento científico de forma a serem desenvolvidos novos produtos e processos destinados a reduzir o esforço humano (JUNG et al., 2009b).

A lei $N^{0} 10.973$ (BRASIL, 2004), define a inovação como introdução de novidade ou aperfeiçoamento no ambiente produtivo ou social que resulte em novos produtos, processos ou serviços. Neste mesmo contexto, a OCDE (2007a) ressalta que à inovação está ligada a um ambiente de incerteza de resultados, onde normalmente a instituição que desenvolve a inovação não é a única beneficiada.

Magalhães (2003) afirma que para avaliação e priorização de projetos é fundamental que os objetivos, interesses e oportunidades destes sejam explicitados e confrontados com os objetivos, interesses e oportunidades das instituições que são afetadas, mesmo que parcialmente, pelo projeto. Para Santos et al. (2007), a definição de projetos prioritários passa pelo alinhamento entre os seus objetivos com os objetivos propostos pelo planejamento estratégico, além dos interesses e oportunidades do negócio da organização. 
Afirma Santoro (2003), que existem muitos modelos e métodos de análise desenvolvidos para criar e avaliar indicadores institucionais e empresariais. Alguns deles inclusive são utilizados pensando no potencial estratégico dos projetos frente à instituições, no entanto, cada um deles possui vantagens e desvantagens, tais como: (i) MAUT - Multiattribute Utility Theory, é um método de comparação quantitativa usado para combinar medidas distintas como custos, riscos e benefícios, juntamente com as preferências individuais dos atores afetados pela classificação dos projetos (THEVENOT et al., 2006; RAMOS, 2010). No entanto, Lyra et al. (1999) afirmam que o método MAUT somente pode ser aplicado à síntese dos critérios, em uma única função, sem considerar a possibilidade de incomparabilidades; (ii) Modelo AHP (Analytic Hierarchy Process) ou Método de Análise Hierárquica é uma forma de desmembrar em critérios hierárquicos um projeto (HOU et al., 2011). Os projetos são comparados aos pares sendo utilizadas matrizes que são elaboradas para permitir a avaliação de critérios quantitativos, qualitativos, tangíveis ou intangíveis. Este método é considerado flexível e de fácil aplicação, mas com êxito apenas em pequenos portfólios (COITINHO, 2007); (iii) Matriz BCG ou Matriz de Crescimento/Parcela de Mercado é uma metodologia prescritiva de análise e reflexão estratégica. Tem por base uma matriz biaxial e tratase de um instrumento particularmente útil e simples de análise estratégica do portfólio para empresas com uma linha de produtos diversificados. Está baseado no princípio de que o sucesso de uma organização é determinado pela otimização dos seus recursos financeiros e de que suas ações diversas deve manter um equilíbrio das suas apostas estratégicas (CAMPOS, 2009); (iv) Matriz McKinsey/GE, trata-se de um modelo desenvolvido pela General Eletric, com a colaboração da consultoria McKinsey, baseado no método BCG. Utiliza uma matriz biaxial de dupla entrada, composta por nove células, que relaciona as variáveis "Posição Competitiva da Organização" (que surge como ordenada) com "Atratividade da Indústria/Segmento de Mercado" (abscissa), cada qual medida com base em uma escala de três posições: Forte, Média e Fraca (CAMPOS, 2009); (v) Método PROMETHEE II, que consiste na construção de uma relação de classificação de indicadores. No seu processo de análise decompõe o objetivo em critérios. As comparações entre 
alternativas são feitas no último nível de decomposição e aos pares através do estabelecimento de margens de preferência inferidas pelos gestores (BEHZADIAN, 2010). Busca uma ordenação do conjunto de alternativas potenciais através do conceito de dominância. É um método que requer informações intercritério correspondente à relativa importância entre os vários objetivos da organização, de forma a criar pesos diferenciados nos critérios. Esses pesos podem ser decorrentes de cálculos técnicos ou apenas expressões de julgamento de valor (MELLO et al., 2006); e (vi) GPORT, que consiste em um modelo de priorização de projetos voltado ao terceiro setor, organizações que possuem iniciativas privadas para fins públicos. Este modelo esta alicerçado em três perspectivas de avaliação, a geral, a técnica e a estratégica, em cada uma das quais são definidas um conjunto de indicadores. A estes indicadores são atribuídas notas que somadas resultam em uma escala de valor estratégico, permitindo facilmente a classificação e hierarquização de projetos. No entanto, o autor deste modelo relaciona-o apenas ao terceiro setor e a avaliação estratégica frente a apenas duas instituições: a instituição financiadora do projeto e a intuição executora, não prevendo os interesses estratégicos de outras entidades que possam ser afetadas pelo projeto (ROCHA et al., 2009).

O sucesso de um projeto depende da participação efetiva dos "stakeholders", que são as partes interessadas de um projeto (PMI, 2008). Analogamente a NBR 16001 (ABNT, 2004) define que as partes interessadas são pessoas ou grupos que têm interesse ou são afetados pelos projetos como o público interno, concorrentes, as instituições públicas e a comunidade em geral.

Morais (2005) salienta a necessidade de serem considerados em cada projeto os Fatores Críticos de Sucessos (FCS). Este autor refere que são os valores e ações ordenadas que possam levar ao cumprimento da missão da instituição. Suzuki (2008) esclarece que os FCS da empresa são as habilidades e os recursos que a empresa necessita para ter êxito. Corroborando, Trkman (2010) refere que os FCS afetam o desenvolvimento dos projetos e indicam prioridades e focos de atenção para a adequada gestão de projetos.

Löbler et al. (2008) afirmam que o FCS de uma organização estão vinculados ao seu Plano Estratégico de Negócio (PEN) que deve ter por base a visão 
estratégica desta. Corroborando, Junior (2008) em seus estudos afirma que a competência da equipe de pesquisa é um importante FCS para a organização. Já Jung et al. (2009b) afirmam que apesar da SCIT/RS apontar que as principais causas de insucessos no Programa de Polos, ao longo dos anos, estão relacionadas às competências dos pesquisadores não é possível atribuir exclusivamente a estes a responsabilidade devido à influências de fatores externos e internos que afetam o Programa.

\subsection{O tratamento de dados e informações aplicado a seleção de projetos}

A necessidade de informações capazes de auxiliar na escolha da melhor decisão mostra-se antiga, já que o indivíduo que gerencia qualquer processo necessita de informações úteis, capazes de detectar tendências, analisar as possibilidades, facilitando a decisão a ser tomada (ANTONELLI, 2009). Corroborando, Santos (2002) afirma que o volume de informações a ser trabalhado na tomada das decisões gerenciais supera largamente a capacidade do processamento humano, exigindo ferramentas de apoio à decisão. A limpeza e padronização dos dados demonstraram ser a etapa mais importante e trabalhosa do processo de análise de dados, dada a grande frequência de informações inconsistentes, incompletas ou com erros de grafia (QUEIROZ et al., 2009).

Macedo e Matos (2010) esclarece que a técnica limpeza de dados refere-se ao tratamento das informações, classificando-a em: (i) Limpeza de campos ausentes, que compreende a eliminação ou controle de campos ausentes em um conjunto de dados. Boscarioli (2005) refere que a maior causa da ausência de dados está relacionada a simples falta de preenchimento; (ii) Limpeza de inconsistências, o que abrange a identificação e a tratamento de valores inconsistentes. Boscarioli (2005) afirma que normalmente tais inconsistências são geradas por digitações incorretas; e (iii) Limpeza de valores não pertencentes ao domínio, que compreende a identificação e a eliminação de valores que não pertençam ao domínio dos atributos do problema. 
Trzeciak et al. (2003) ressaltam a necessidade de identificar e tratar as redundâncias, as quais podem ser reflexo de termos diferentes para expressar um mesmo objeto, pessoa, lugar ou conceito do mundo real, sendo esta redundância causada principalmente por visões de negócio diferentes dos stakeholders.

Penteado (2009) relata em seu trabalho a necessidade do processamento de informações qualitativas de forma a possibilitar um tratamento adequado destas informações, recomendando para isso a lógica Fuzzy. Sousa e Porcile (2009) denominam a lógica Fuzzy como nebulosa, pois não acata ou gera resultados objetivos em um primeiro olhar. Já Silva e Lima (2009) mostram que esta lógica permite a modelagem matemática do raciocínio humano, manipulando as informações em um ambiente de incerteza, classificando assim conceitos sobre determinada variável através da composição de Conjuntos Fuzzy, onde as variáveis linguísticas de valor são atribuídas a conjuntos matemáticos com margens sobrepostas.

Para Demo (2008), o ser humano formula conceitos para "distinguir as coisas", no entanto estes conceitos possuem habitualmente margens sobrepostas, sendo assim imprecisos, com pretensões de impor precisão. Desta forma ressalta-se a necessidade da utilização de critérios específicos para o tratamento matemático de variáveis linguísticas.

\section{ESTUDO APLICADO}

\subsection{Cenário}

A proposta de Modelo para Avaliação do Potencial Estratégico de Projetos de P\&D de Inovações Tecnológicas foi desenvolvida com o intuito de disponibilizar ao Programa de Apoio a Polos de Inovação Tecnológica do Estado do Rio Grande do Sul uma ferramenta para seleção e classificação de projetos. Este Programa conta atualmente com 22 Polos implantados em 25 regiões do Estado do RS correspondentes aos COREDES - Conselhos Regionais de Desenvolvimento (SCT/RS, 2010). 


\subsection{Problema de pesquisa}

Jung et al. (2009b) definem um Polo de Inovação Tecnológica como um sistema composto por uma comunidade de pesquisa e uma comunidade de parceiros sociais interessados na difusão e utilização das tecnologias desenvovidas. Estes parceiros podem ser os COREDES, instituições públicas, organizações empresariais, cooperativas industriais, comerciais e de serviços, sindicatos e outros atores.

A lei $N^{\circ} 11.179$ (RS, 1998) atribui a cada COREDE a responsabilidade pela identificação de demandas regionais através de Consulta Popular. Jung et al. (2008a) afirma que o Governo do Estado, embasado nestas demandas, elabora um Termo de Referência que fixa a prioridade a ser atendida pelo processo de P\&D do Programa de Apoio a Polos. Posteriormente, é lançado um edital pela Divisão de Polos da SCT/RS que prevê e fixa os recursos financeiros para custear a aquisição de materiais permanentes e de consumo destinados à execução de um ou mais projetos para cada Polo que integra o Programa (JUNG, et al., 2008a).

Os termos de referência de 2008 e 2009, publicados pela SCT, estabelecem o interesse do Programa de Apoio a Polos de Inovações Tecnológicas em promover a integração da comunidade científica com a iniciativa privada, oferecendo incentivos a projetos que possuem a participação de uma ou mais "instituição parceira", definida como uma instituição ou empresa privada responsável por pelo menos 10\% dos custos do projeto proposto ao Programa (SCT, 2010d) e (SCT,2010e).

Vargas et al. (1998) esclarecem que uma Unidade Executora (UE) é uma instituição de ensino superior ou centro de pesquisa estabelecido na região de um determinado Polo de Inovação Tecnológica referendado pelo respectivo COREDE (Conselho Regional de Desenvolvimento). Esta instituição uma vez integrante do Programa de Polos está habilitada a propor e realizar projetos de interesse regional. Os autores referem que a formalização do Polo perante o Governo do Estado do RS é realizada por meio de um Protocolo de Intenções firmado entre a Secretaria da Ciência, Inovação e Desenvolvimento Tecnológico do RS, o COREDE e as diversas instituições representativas da região como Unidades Executoras, Prefeituras Municipais, associações de classe, entre outras (VARGAS et al., 1998). 
Jung et al. (2008a) estudaram o modelo do processo de P\&D do Programa de Polos e mostram que antes da análise de viabilidade e aprovação pela SCIT/RS a seleção é realizada pelo Gestor do Polo, ver Figura 1.

Cada Gestor para avaliar, selecionar e classificar os projetos a serem submetidos a SCIT/RS utiliza diversos meios, qualitativos e ou quantitativos, que são baseados nos princípios do Programa, demandas regionais e interesses das Unidades Executoras. Estes "meios" quase que na totalidade não são instrumentalizados por uma ferramenta adequada (JUNG et al., 2008a).

Figura 1 - Modelo que descreve o processo de P\&D do Programa de Polos do RS

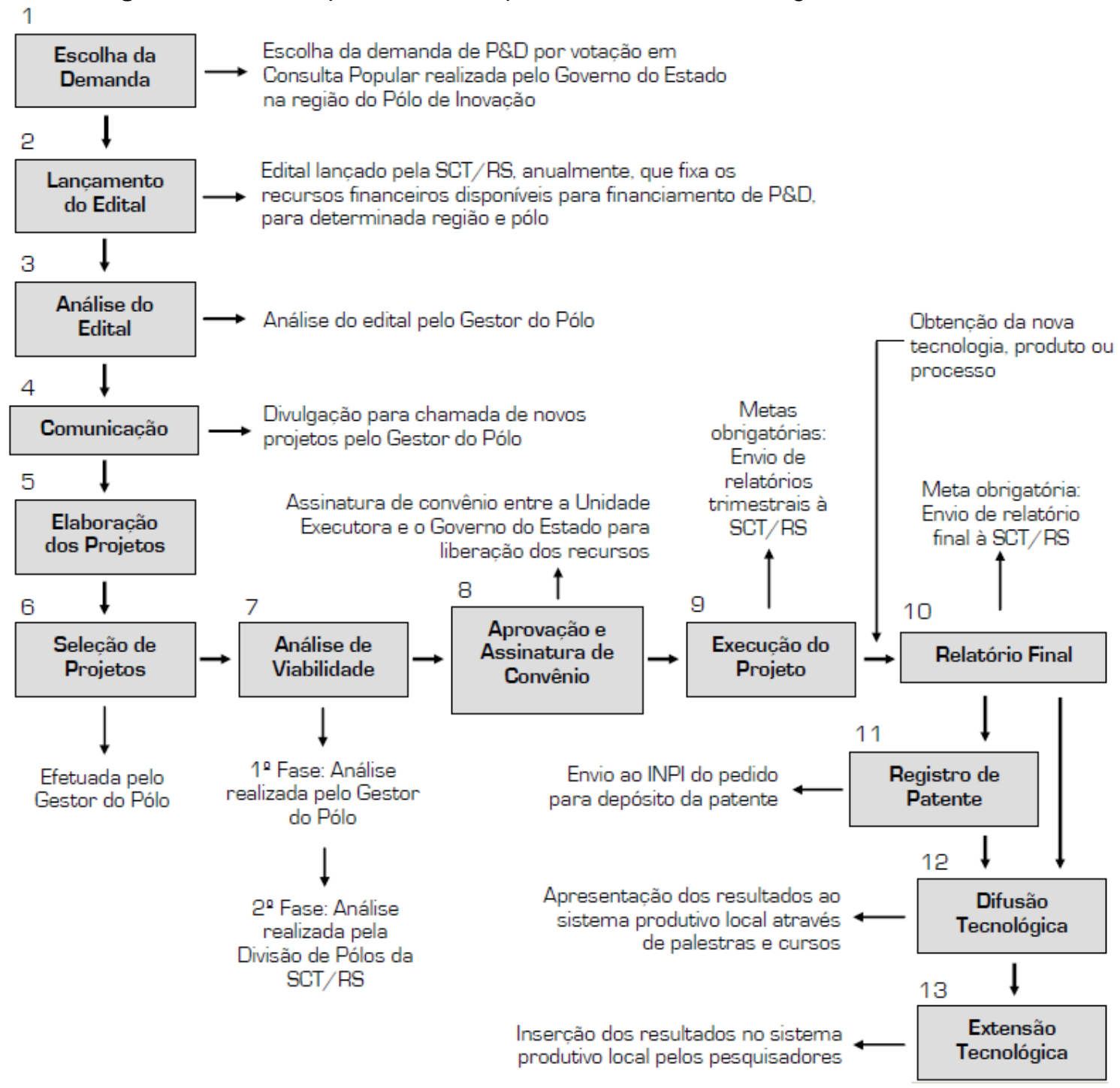

Fonte: Jung et al. (2008a, p. 6).

Revista Produção Online, Florianópolis, SC, v.13, n. 3, p. 1167-1196, jul./set. 2013. 
Jung et al. (2009b) identificaram problemas no processo de avaliação e seleção de projetos do Programa de Polos de Inovação do RS, entre estes ressaltase: (i) Interferência política da instituição executora ou de entidades externas no momento da determinação das prioridades e elaboração das propostas de projetos; e (ii) Inexistência no Programa de um sistema para gestão de projetos.

Neste caso, Padovani et al. (2010) referem que a gestão de projetos deve possuir em todas etapas meios para oportunizar avaliações voltadas à melhoria do processo de tomada de decisão. Corroborando, Kleinsmann e Valkenburg (2005) afirmam que o processo de inovação requer a minimização de interferências internas e externas adversas.

\subsection{Método de pesquisa}

A Figura 2 mostra o método utilizado para o desenvolvimento da pesquisa. $\mathrm{Na}$ sequência são descritas as etapas e procedimentos metodológicos.

Figura 2 - Diagrama do método de pesquisa

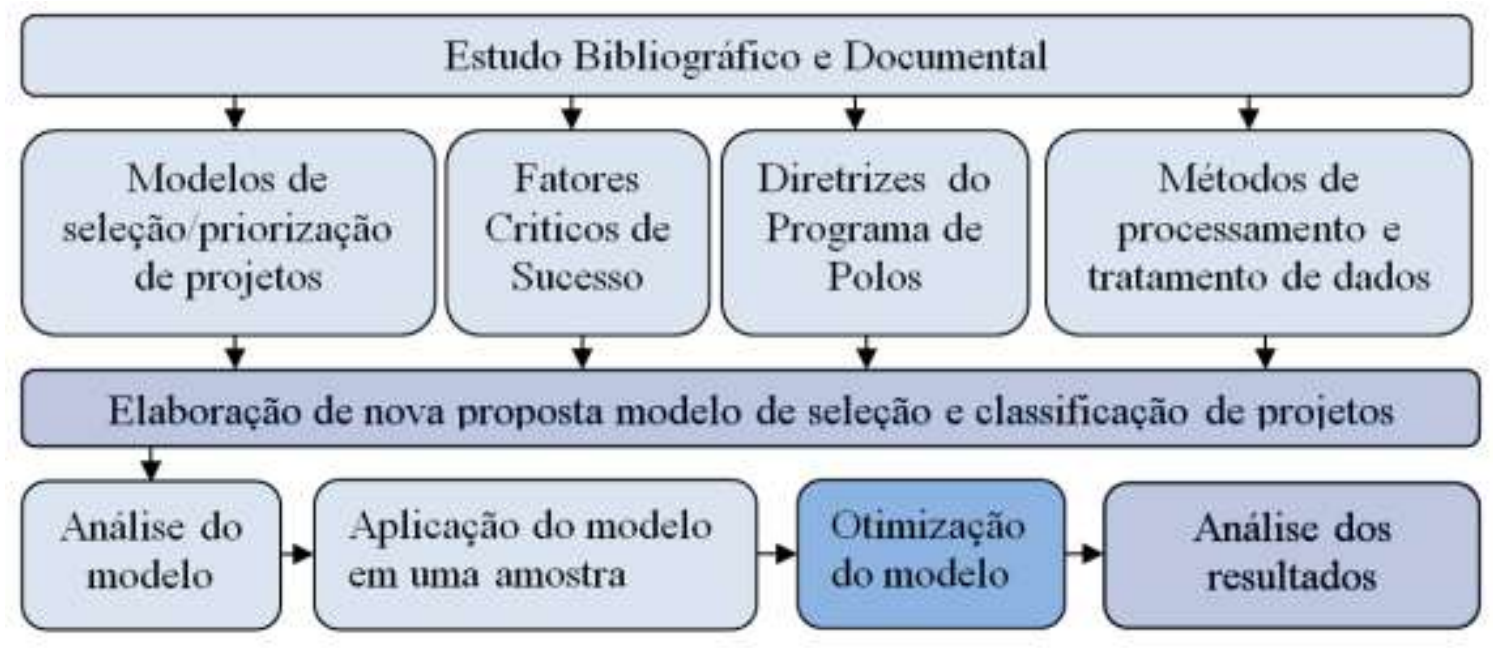

Foi realizado um estudo bibliográfico e documental sobre modelos para seleção e priorização de projetos, Fatores Críticos de Sucesso, diretrizes do Programa de Polos e métodos para processamento e tratamento de dados. 
O estudo viabilizou identificar uma série de indicadores representativos, tanto do potencial estratégico quanto da viabilidade de execução dos projetos, sendo que estes indicadores, em sua maioria, são de natureza qualitativa. Segundo Demo (2008) este tipo de abordagem pode implicar em uma interpretação da realidade sobre o ponto de vista de cada indivíduo. Por esta razão foram utilizadas técnicas de processamento de dados baseadas nos princípios metodológicos de Hora et al. (2010), Macedo e Matos (2010), Antonelli (2009), Porcile (2009), Silva e Lima (2009), Penteado (2009), Pereira et al. (2008), Demo (2008), Queiroz et al. (2008), Trzeciak et al. (2003) que viabilizaram formulação e proposição de indicadores qualitativos em forma de variáveis quantitativas que segundo Jung (2010) devem apresentar apenas valores numéricos.

$\mathrm{Na}$ sequência foi desenvolvido o Modelo para Avaliação do Potencial Estratégico de projetos de P\&D. Posteriormente foi realizada uma verificação do Modelo através da aplicação em uma amostra dos projetos aprovados pelo Programa de Polos de Inovação Tecnológica do RS.

O objetivo desta avaliação foi averiguar o enquadramento destes projetos na escala de valor do modelo proposto permitindo assim uma análise deste, além da atribuição de um valor de referência para a escala de valor do modelo. Segundo Jung (2010), esta medida permite classificar os procedimento desta pesquisa como experimental.

\subsection{Descrição do modelo proposto}

O modelo para avaliação do potencial estratégico de projetos de P\&D foi elaborado a partir de um Conjunto de Indicadores, desenvolvimento de uma Plataforma de Aquisição e Tratamento de Dados, e uma Plataforma para Comparação de Projetos.

\subsubsection{Conjunto de indicadores}

O primeiro conjunto de indicadores utilizados neste modelo possui a função de determinar a viabilidade de enquadramento da pesquisa ao Programa de Polos, 
de forma a evitar antecipadamente a análise de projetos que não poderão ser executados e financiados pelo Programa. Estes indicadores são considerados como critérios eliminatórios e definem se o projeto é "adequado" ou "não adequado".

Os indicadores utilizados para esta função são: (i) Natureza da pesquisa: que permite classificar a pesquisa como Básica ou Aplicada. Como este modelo foi desenvolvido para avaliar projetos de inovação tecnológica apenas as pesquisas de natureza Aplicada são consideradas adequadas; (ii) Valor do projeto adequado ao orçamento do Programa: o enquadramento do projeto aos recursos disponíveis é um item fundamental e determinado pelos editais; (iii) Adequação da linha de pesquisa do projeto de pesquisa ao edital: diversos editais limitam as linhas de pesquisa como, por exemplo, os Termos de Referência 2008 (SCT, 2010e) e 2009 (SCT, 2010d); (iv) Adequação da linha de pesquisa ao polo: as linhas de pesquisas do polo local traduzem a vocação estratégica da região a qual o Polo está vinculado. Neste caso, Jung (2008b) afirma que os Gestores dos Polos analisam a viabilidade dos projetos principalmente pelo enquadramento da proposta nas linhas de pesquisa do Polo local; e (v) Adequação da linha de pesquisa a executora: este indicador possui uma relação análoga ao anterior.

Uma vez atendidos estes critérios os projetos estão aptos à análise que é realizada pelo segundo conjunto de indicadores que são considerados como critérios de classificação.

Estes indicadores foram elaborados com base no Manual de Frascati (OCDE, 2007b). Os indicadores foram classificados em categorias para permitir a análise de diferentes fatores, a saber: (i) Categoria Insumos; (ii) Categoria Produtos (Resultados), divida nas subcategorias: (a) Produtos Diretos e (b) Inovação; e (iii) Categoria Impacto, dividida nas subcategorias: (a) $\mathrm{Na}$ Instituição e (b) $\mathrm{Na}$ Sociedade. Cada subcategoria é formada por diversos indicadores que possibilitam pontuar os projetos com uma ponderação feita em função do grau de importância para cada ator, ver Figura 3. 
Figura 3 - Segundo conjunto de indicadores do modelo

\begin{tabular}{|c|c|c|}
\hline \multicolumn{2}{|c|}{ Pontuação Geral } & $\begin{array}{c}\text { Ponderaçã } \\
\text { o dos } \\
\text { atores }\end{array}$ \\
\hline \multicolumn{2}{|l|}{} &
\end{tabular}

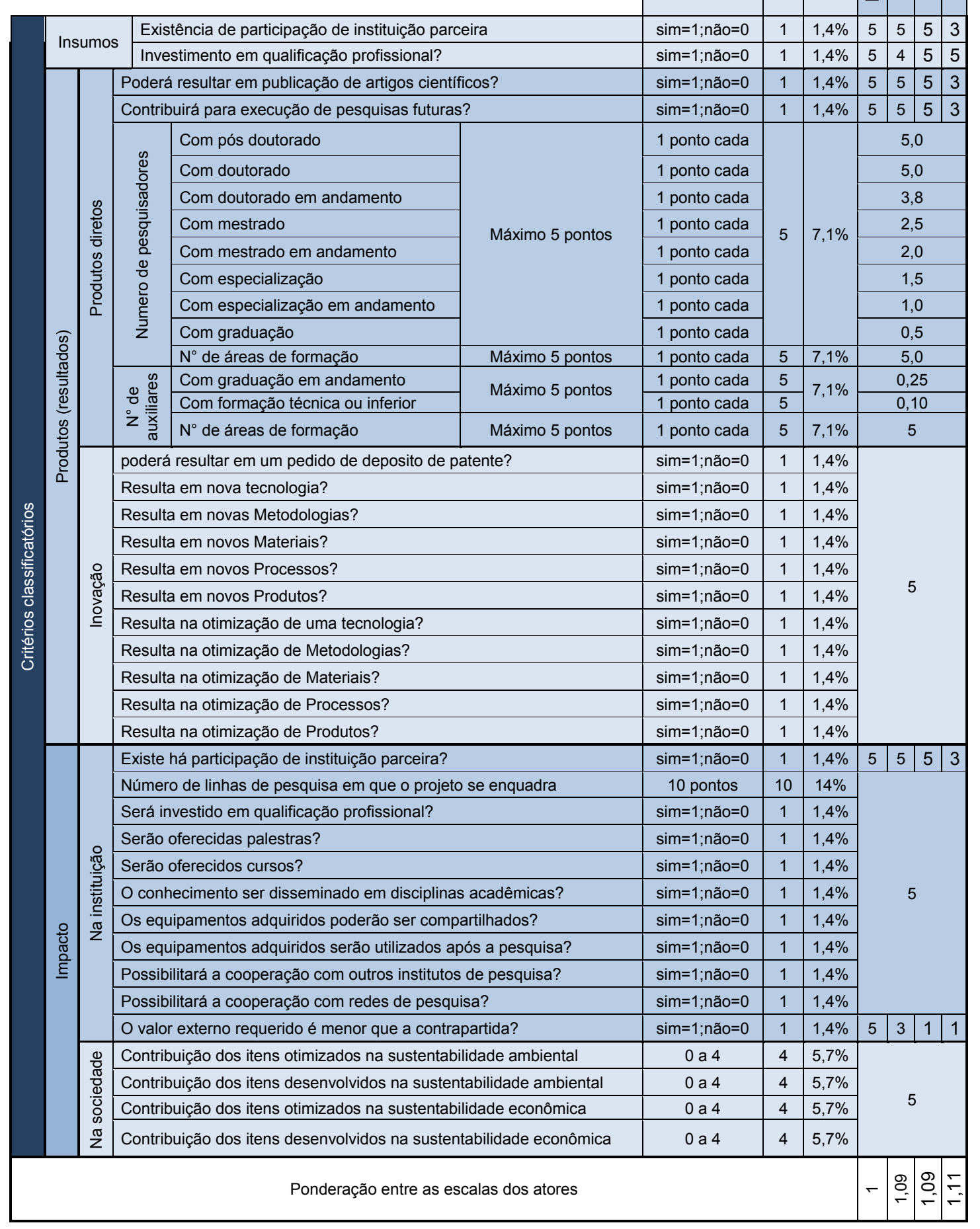

Revista Produção Online, Florianópolis, SC, v.13, n. 3, p. 1167-1196, jul./set. 2013. 
Os indicadores classificados na Categoria Insumos são: (i) Existência de participação de instituição parceira; e (ii) Investimento em qualificação profissional. Quando existentes estes insumos representam a possibilidade de investimento financeiro adicional do parceiro na pesquisa e o desenvolvimento e aperfeiçoamento das habilidades da equipe de pesquisa.

Os indicadores classificados na Categoria Produtos (Resultados) foram baseados nos estudos de Francisco (2002) que mostra os possíveis resultados que podem alcançar projetos de pesquisa em relação à produção científica, inovação e contribuições para futuras pesquisas. No entanto, como esta avaliação é feita antes da execução dos projetos isto implica em uma dificuldade para prever resultados concretos. Em função disto, os indicadores foram associados através da lógica nebulosa de forma a obter-se características relevantes sendo propostas duas subcategorias, a saber: Produtos Diretos e Inovação.

A subcategoria Produtos Diretos divide-se em: (i) Publicação Científica, esta característica indica a possibilidade de publicação dos conhecimentos obtidos na pesquisa; (ii) Contribuição para Execução de Pesquisas Futuras; e (iii) Número de participantes da equipe de pesquisa, sendo (a) Números de Pesquisadores e (b) Número de Auxiliares, considerando as respectivas formações acadêmicas. A pontuação proposta para esta subcategoria é análoga à utilizada pela SCIT/RS no Programa Pro-Inovação (SCT, 2010c).

A subcategoria Inovação engloba os seguintes possíveis resultados: (i) Possibilidade de pedido de depósito de patente, neste caso a OCDE (2007a) afirma que o processo para concessão de patente é muito longo, recomendando a utilização do pedido de depósito de patente como indicador. A SCIT/RS através do Termo de Referência para Apresentação de Projetos (SCT, 2010d) estabelece prioridade para projetos passíveis de propriedade intelectual; (ii) Desenvolvimento de novas tecnologias, metodologias, materiais, processos e produtos, este indicador baseado no Manual de Oslo (OCDE, 2007a). O Termo de Referência para Apresentação de Projetos (SCT, 2010d) prioriza os projetos relacionados com este indicador; e (iii) Otimização de tecnologias, metodologias, materiais, processos e produtos, que é baseado de forma análoga ao anterior. 
Os indicadores classificados na Categoria Impacto da pesquisa representam $70 \%$ da pontuação da escala de valor desta proposta. Esta classificação é dividida em duas subcategorias, a saber: Na Instituição e Na Sociedade.

A subcategoria que avalia o impacto $\mathrm{Na}$ Instituição possui indicadores que se destinam a identificar a possibilidade de serem efetuadas parcerias com outras instituições de pesquisa, se o projeto pode ser enquadrado em mais de uma linha de pesquisa, oportunizar investimentos em qualificação, serem ofertados a comunidade acadêmica e em geral palestras e cursos, se os conhecimentos produzidos podem ser disseminados em disciplinas curriculares na instituição, entre outras atividades que se caracterizam como indicadores de difusão. Corroborando, o Manual de Oslo (OCDE, 2007a) afirma que a difusão do conhecimento é fundamental para o crescimento econômico, o desenvolvimento e o bem-estar das nações. Esta subcategoria também prevê a viabilidade de utilização dos equipamentos a serem adquiridos em futuras pesquisas.

A subcategoria que avalia o impacto $\mathrm{Na}$ Sociedade considera indicadores que levam em conta o impacto econômico e ambiental na sociedade em conformidade com as recomendações do Manual de Oslo sobre impacto da inovação (OCDE, 2007a). Para tanto, foram propostos indicadores para avaliar a contribuição em relação a otimização e desenvolvimento para sustentabilidade ambiental, otimização e desenvolvimento obtido para fins econômicos.

\subsubsection{Plataforma de aquisição e tratamento de dados}

Hora et al. (2010) afirmam haver maior transparência no tratamento de dados quando utilizadas planilhas eletrônicas. Estas permitem um acompanhamento do processo de forma quantitativa e simbólica, facilitando também cálculos matemáticos. Desta forma, optou-se pelo uso do software aplicativo Microsoft Excel para o desenvolvimento do modelo.

Para facilitar o uso da planilha foi elaborado e inserido um menu que consiste em um conjunto de links para auxiliar o usuário efetuar o preenchimento e 
verificação de dados e, posterior, visualização dos resultados da análise do potencial estratégico dos projetos, ver Figura 4.

Figura 4 - Tela de entrada da planilha eletrônica (menu)

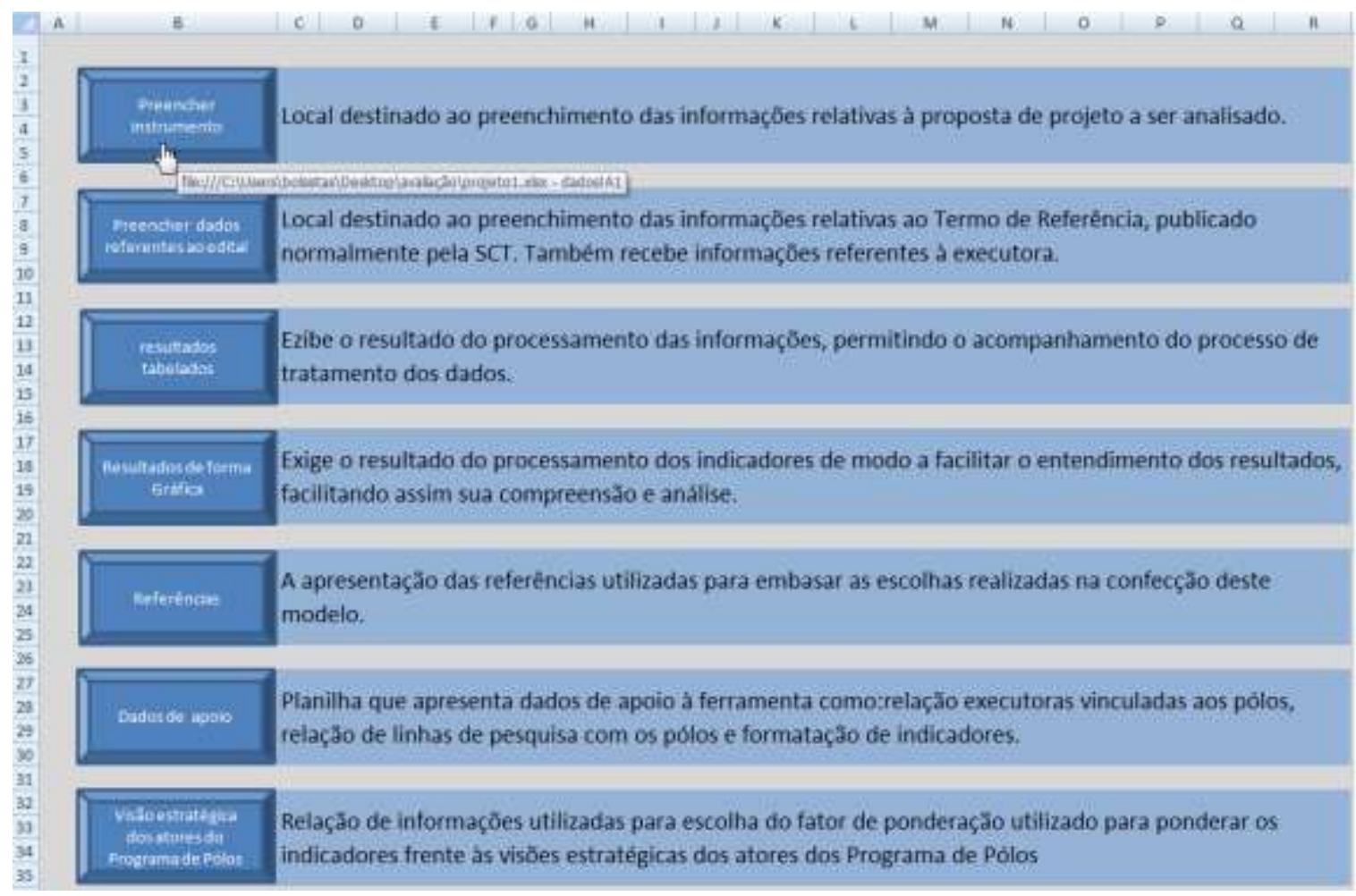

A aquisição de dados no modelo foi planejada de forma a serem evitadas inconsistências como: (i) Falta de compreensão do indicador - veja que na parte superior da Figura 5 está destacado um "comentário" com uma breve descrição do campo ao qual este fica vinculado para facilitar a compreensão pelo usuário.

Figura 5 - Mensagem de alerta associada um comentário explicativo

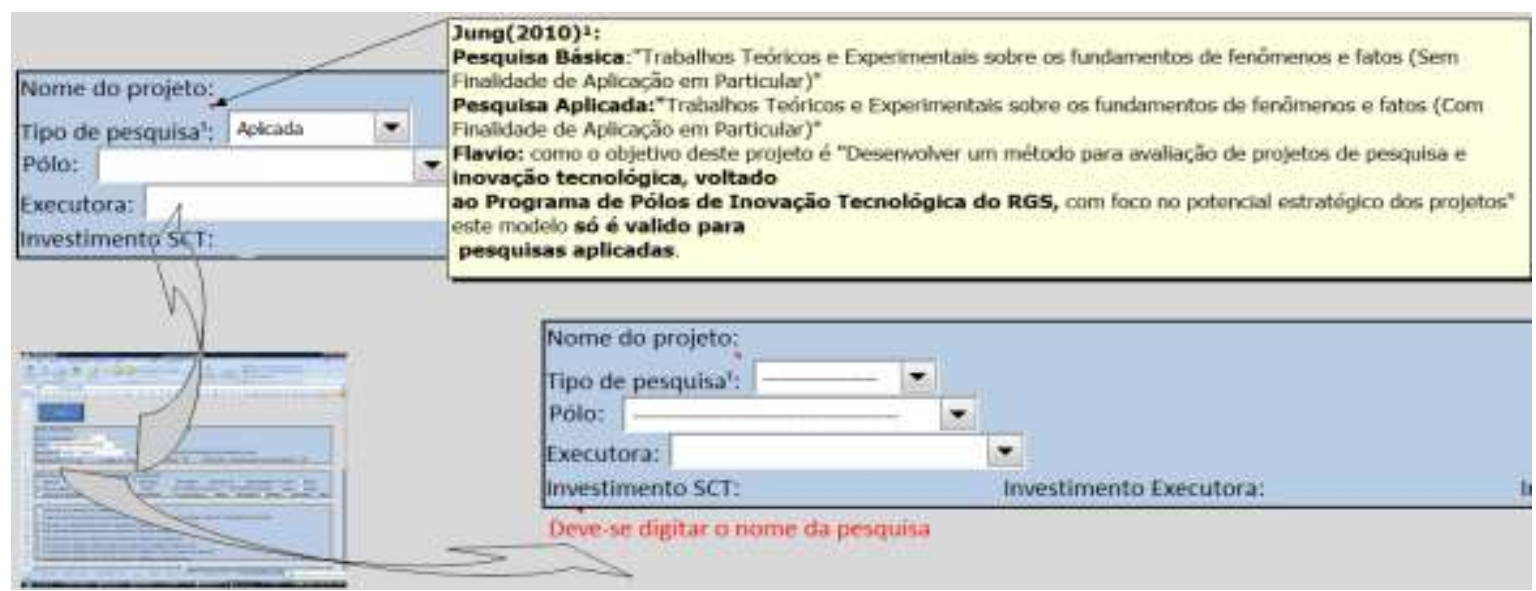

Revista Produção Online, Florianópolis, SC, v.13, n. 3, p. 1167-1196, jul./set. 2013. 
(ii) Falta de preenchimento - quando faltar o preenchimento do "nome da pesquisa" o sistema alertará através de uma mensagem indicando o não preenchimento do campo, ver na parte inferior da Figura 5.

(iii) Limitação de indicadores - ver na Figura 6, parte inferior, que existe uma "caixa de seleção" que retorna a informação de falso ou verdadeiro para estabelecer neste caso apenas uma relação ou não da pesquisa com o item analisado sem considerar a intensidade desta relação.

Figura 6 - Caixa de múltipla escolha e caixa de seleção

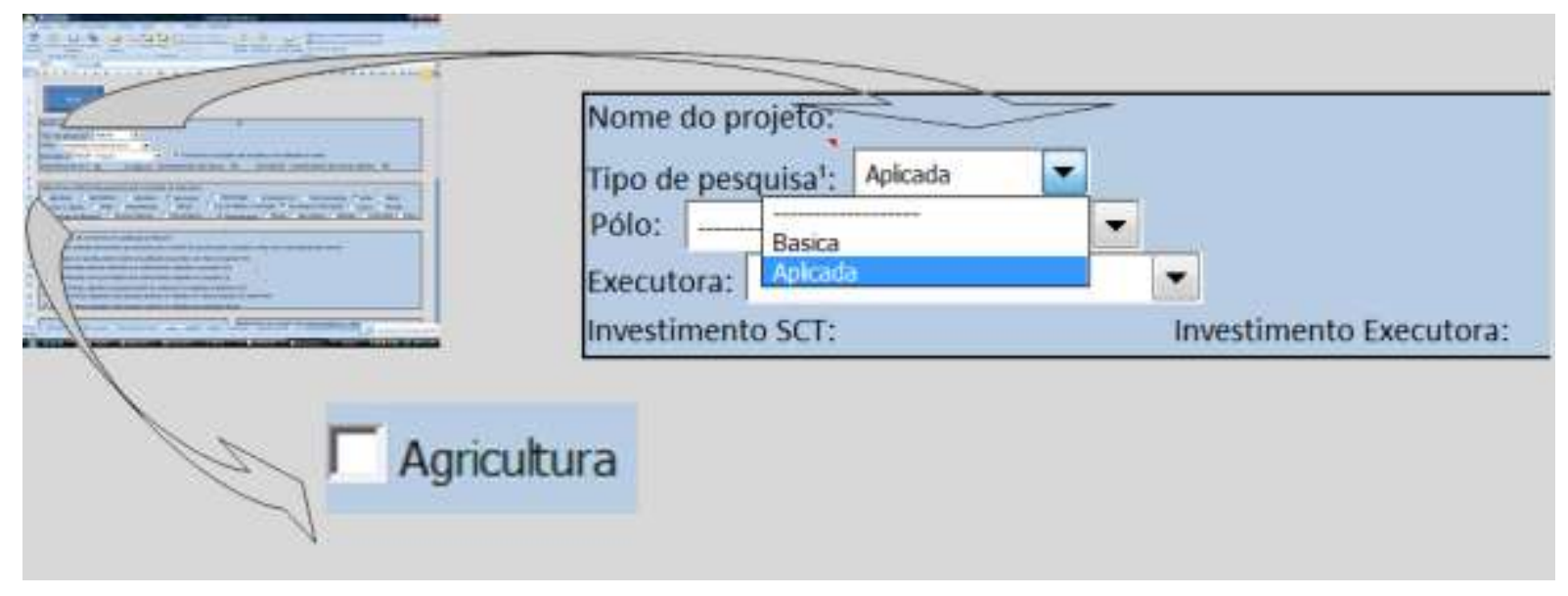

(iv) Redundâncias e preenchimento incorreto - as redundâncias e o preenchimento incorreto são controlados pelo sistema através da utilização de campos de múltipla escolha, ver Figura 6.

Ressalta-se que os cuidados com a aquisição e o tratamento de dados nas planilhas do modelo proposto resultam não apenas na orientação de preenchimento e controle dos dados informados, mas facilitam o uso do modelo proposto.

Os dados coletados são utilizados de forma a realizar inicialmente duas funções distintas: (i) Identificar se o projeto a ser analisado realmente se enquadra nos critérios do Programa de Polos da SCIT/RS; e (ii) Pontuar numericamente projetos de inovação tecnológica.

Diversos indicadores foram agrupados de forma a verificar se o projeto analisado realmente atende aos quesitos mínimos do Programa e se consiste em 
um projeto de inovação tecnológica, de tal forma que não atendendo a estes quesitos sua pontuação de valor estratégico será zerada.

A escala de valor estratégico segue os princípios da lógica nebulosa, onde indicadores qualitativos são agrupados e formatados para representar uma característica estratégica relevante no sistema formado pelo Programa de Polos, graduando seu peso no instrumento de avaliação.

A escala é formada pelo somatório atribuído em cada item de análise, conforme a visão estratégica de cada ator - Unidade Executora, Programa de Polos, Polo de Inovação e COREDE. Cada característica estratégica também é ponderada frente aos interesses destes atores evidenciando a importância do projeto analisado para estas. Tal ponderação de valores faz-se necessária para garantir a representatividade dos atores do Programa na escala de valor estratégico geral do modelo de avaliação proposto.

As escalas de valor estratégico criadas para este modelo propiciam uma visão geral da relação do projeto de pesquisa proposto com os stakeholders do Programa de Polos. Para facilitar a leitura destas informações foi elaborado um conjunto de gráficos que organizam as informações, apresentando de forma visual os pontos fortes e fracos de cada projeto analisado.

\subsubsection{Plataforma para comparação de projetos}

As etapas já descritas permitem uma análise apenas de um projeto por planilha eletrônica - através do uso de um arquivo. Para realizar a análise de um conjunto de projetos foi proposto adicionalmente um segundo modelo de planilha eletrônica capaz de relacionar entre si os projetos de pesquisa de interesse. A Figura 7 ilustra a vinculação de vários projetos a um modelo de planilha capaz de processá-los. 
Figura 7 - Forma para múltipla aquisição de dados (vários arquivos)

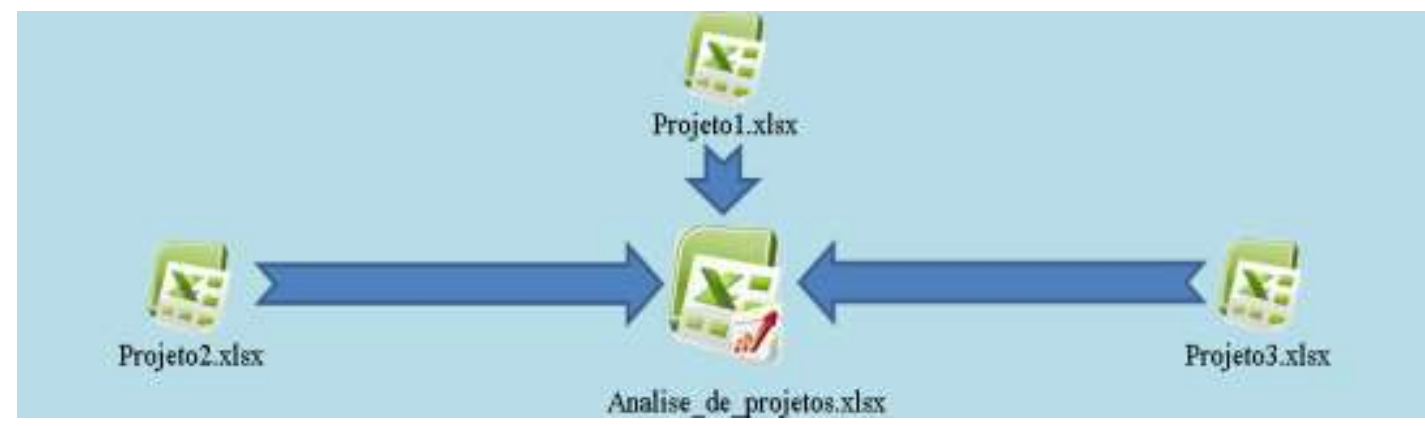

Cada projeto é analisado individualmente em um arquivo padrão que recebe o nome de "projetoX.xlsx", onde o "X" representa um número sequencial que é atribuído pelo operador para diferenciar os projetos de pesquisa. $O$ arquivo "analise_de_projetos.xlsx" copia os dados dos arquivos de projetos que estão na mesma pasta do sistema operacional formando uma tabela que permite a comparação direta entre os indicadores de cada projeto de pesquisa, bem como suas respectivas pontuações de valor estratégico, ver Figura 7. Esta planilha de análise de projetos gera modelos gráficos, que não só classificam os projetos por ordem de pontuação, como também permitem visualizar uma relação entre os pontos fortes e fracos dos projetos destacando a relação estratégica destes com os atores do Programa de Polos.

\subsubsection{Recursos operacionais do modelo para avaliação de projetos}

Para demonstrar as vantagens e limitações do modelo de avaliação proposto na sequência é apresentada uma análise a partir da aplicação em um projeto de pesquisa. A Figura 8 mostra o resultado em forma gráfica apresentado pelo modelo proposto após o preenchimento dos dados relativos a um projeto. Na parte superior esquerda da Figura 8 existe um "botão" denominado "Início" o qual, quando pressionado, conduz à tela inicial do sistema que dá acesso a todas telas do modelo. Sob o botão "início" consta um gráfico que mostra a importância do valor estratégico atribuída ao projeto de pesquisa em relação a cada um dos atores do Programa. 
Figura 8 - Tela do sistema que mostra os resultados em forma de modelos gráficos

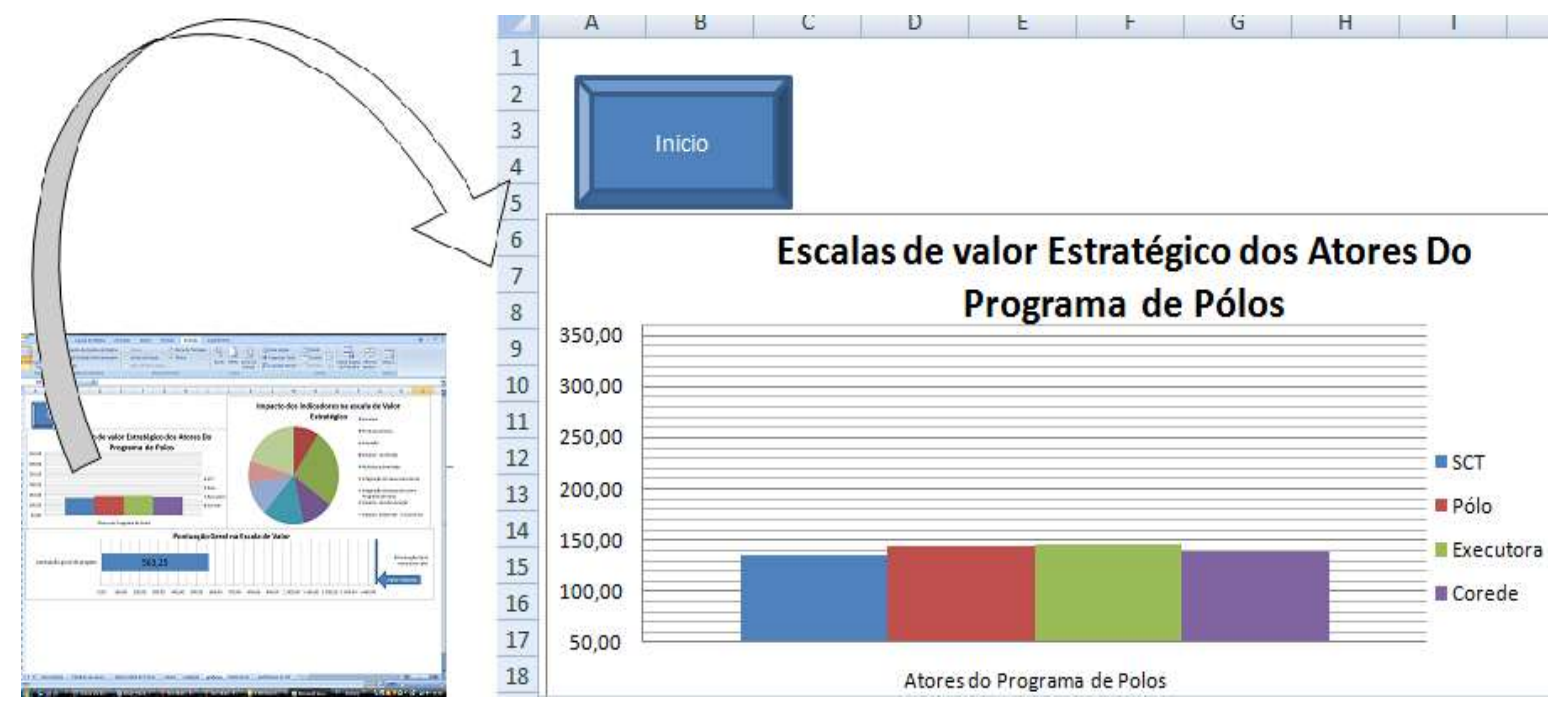

O modelo pode apresentar de forma gráfica os pontos fortes e fracos de um projeto de pesquisa em análise, ver Figura 9.

Figura 9 - Tela do sistema que mostra o impacto dos indicadores na escala de valor estratégico

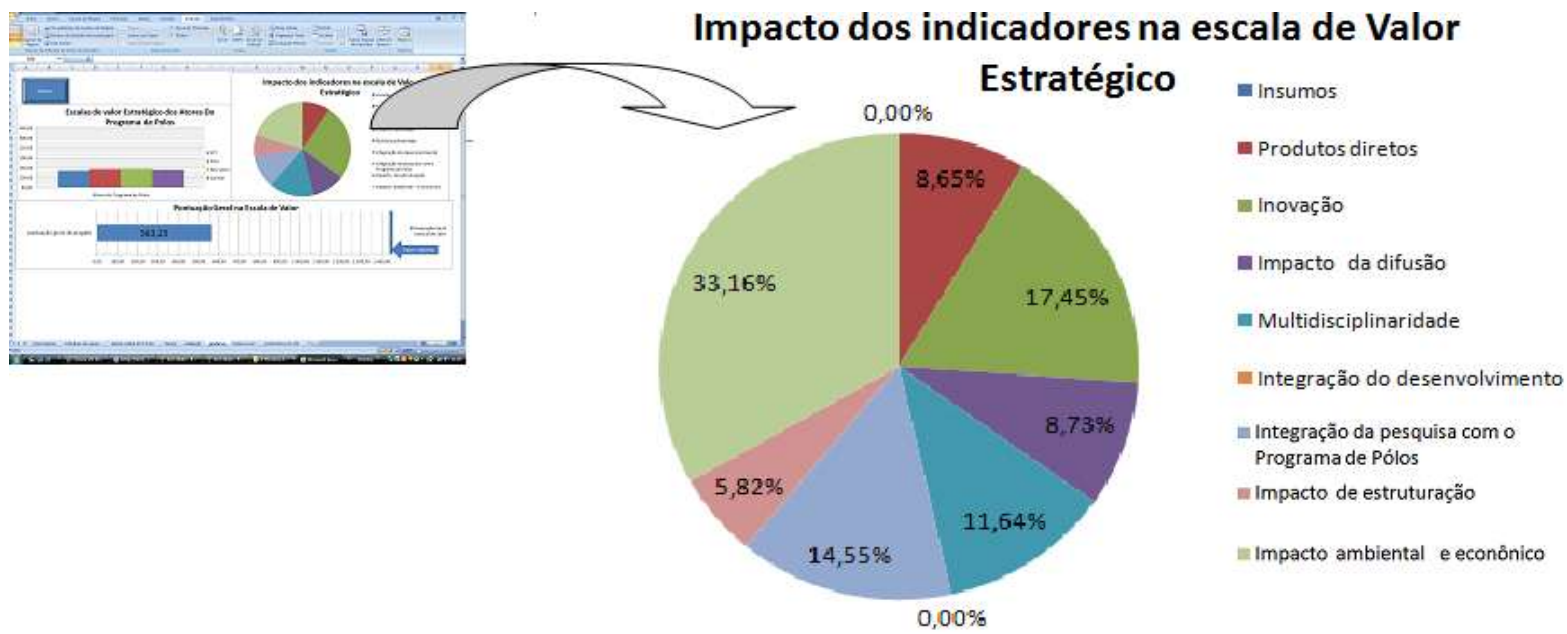

Um importante recurso do modelo para avaliação de projetos consiste na disponibilização de uma "escala de pontuação geral" que mostra o valor estratégico do projeto, ver Figura 10.

Revista Produção Online, Florianópolis, SC, v.13, n. 3, p. 1167-1196, jul./set. 2013. 
Figura 10 - Tela do sistema que mostra a pontuação geral de um projeto na escala de valor

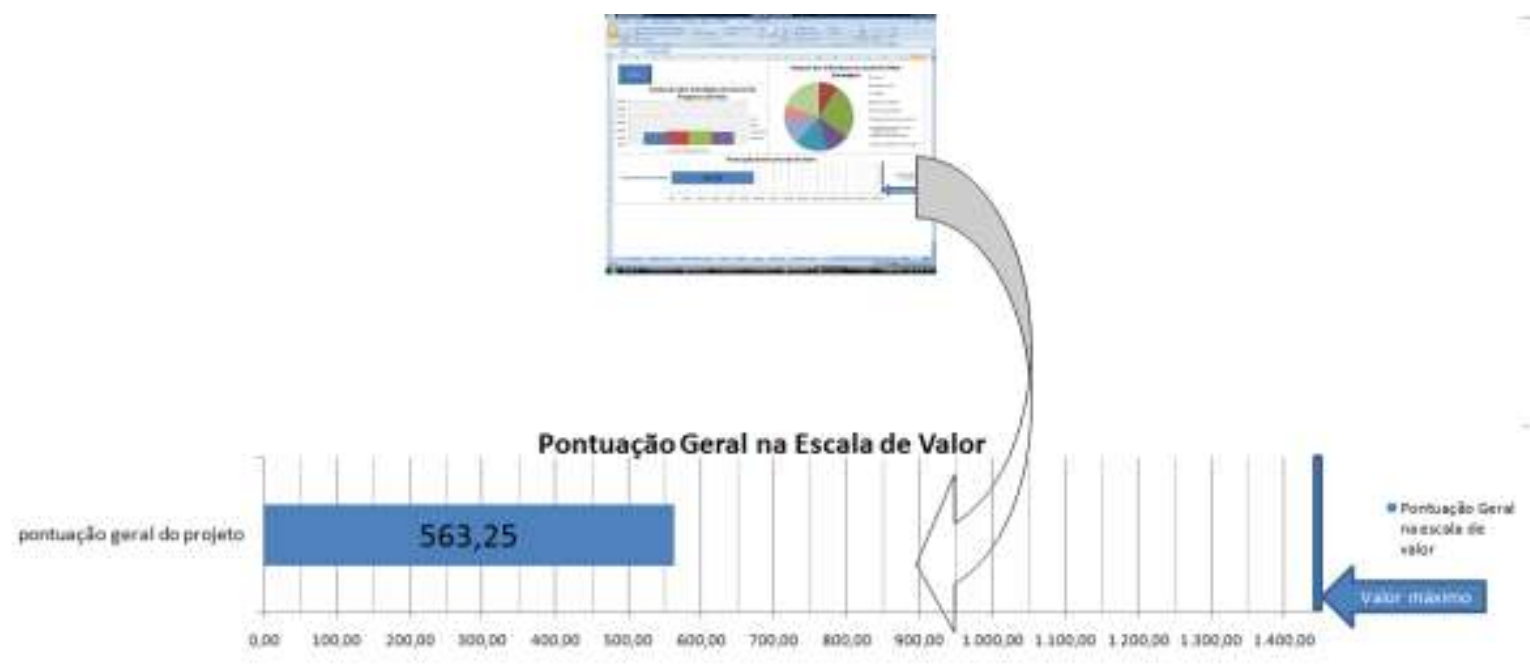

\section{VERIFICAÇÃO DO MODELO PROPOSTO}

Para verificar inconsistências no sistema operacional do modelo foi realizada a aplicação em uma amostra composta por dois projetos. Os projetos foram selecionados pelos seguintes critérios: (i) Projetos dos quais o autor não tenha participado; (ii) Projetos com a execução em andamento, pois este fato indica que estes foram considerados estratégicos pelo Programa de Polos; e (iii) Fácil acesso aos pesquisadores responsáveis pelos Projetos.

Inicialmente, foram selecionados e avaliados pelo autor dois projetos de pesquisa - Projeto (A) e Projeto (B). Na sequência, este procedimento foi realizado novamente pelos pesquisadores envolvidos nos respectivos projetos.

Os resultados obtidos entre a avaliação destes projetos pelo autor e a realizada pelos pesquisadores responsáveis pelos projetos apresentou uma diferença de $0,39 \%$ sobre a escala de valor estratégico do Projeto $(A)$ e $8,95 \%$ sobre a escala de valor do projeto (B). Esta diferença verificada no projeto (B) pode ter sido em função das inconsistências geradas pela interpretação dos dados. Desta forma ficou evidente a necessidade de uma maior atenção quando da interpretação dos dados dos projetos de pesquisa.

Para demonstrar a efetividade do modelo de avaliação proposto, após a execução dos procedimentos operacionais já descritos nas seções anteriores, pode 
ser observado na Figura 11 o resultado da comparação entre os projetos (A) e (B) em relação a pontuação obtida em função de cada ator do Programa.

Figura 11 - Tela que mostra a comparação entre projetos $(A)$ e $(B)$ em escala geral estratégica

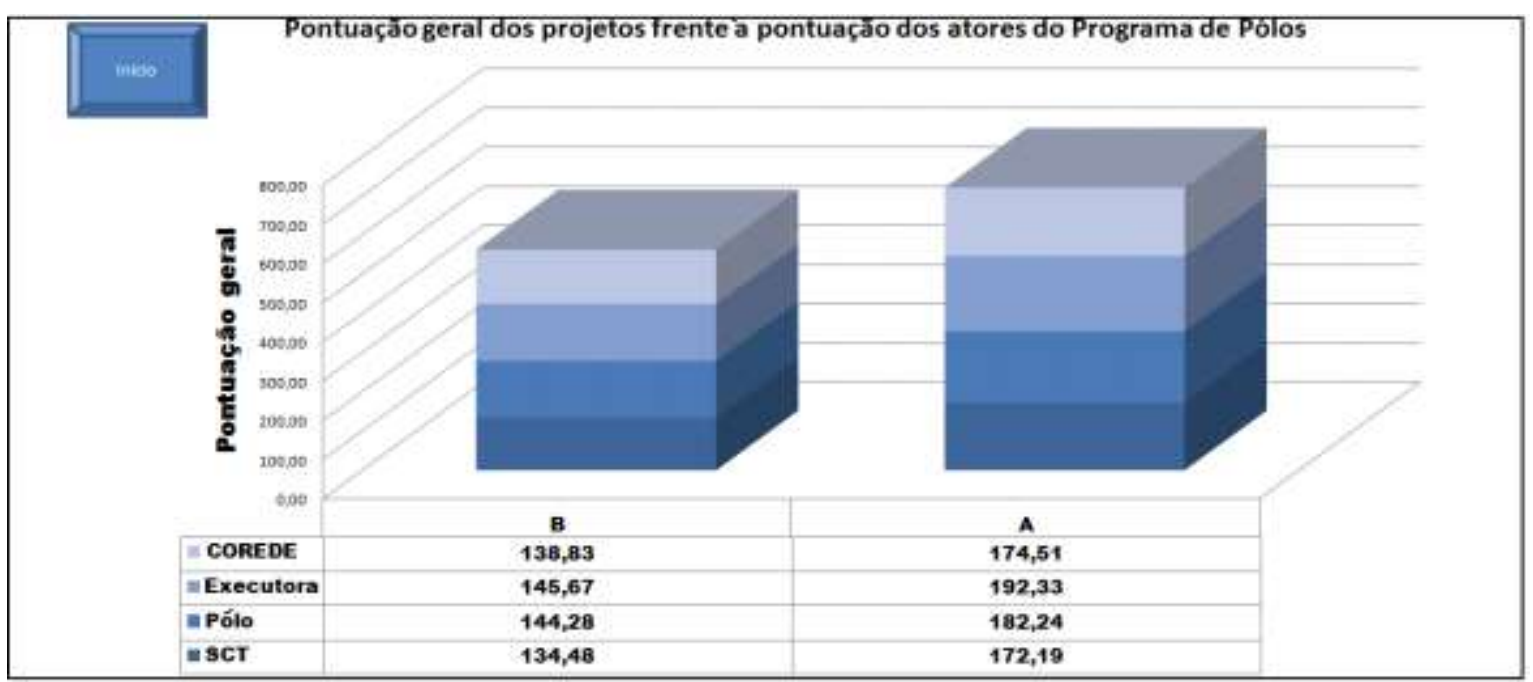

Apesar da escala geral de valor estratégico do modelo já permitir a seleção e classificação de projetos pelo usuário, também foi desenvolvido um recurso que poderá facilitar a comparação de forma detalhada dos projetos. Este recurso decompõe a escala geral de valor estratégico através de diversos indicadores, ver a Figura 12.

Em relação aos dois projetos que foram avaliados para fins de verificação do modelo pode-se afirmar que o projeto (B) apresenta um maior grau de inovação do que o projeto $(A)$, apesar de possuir uma pontuação geral menor. Este tipo de análise pode tornar-se útil quando os projetos apresentarem pouca diferença em sua escala geral de valor estratégico. 
Figura 12 - Tela que mostra a comparação entre projetos de pesquisa de forma detalhada

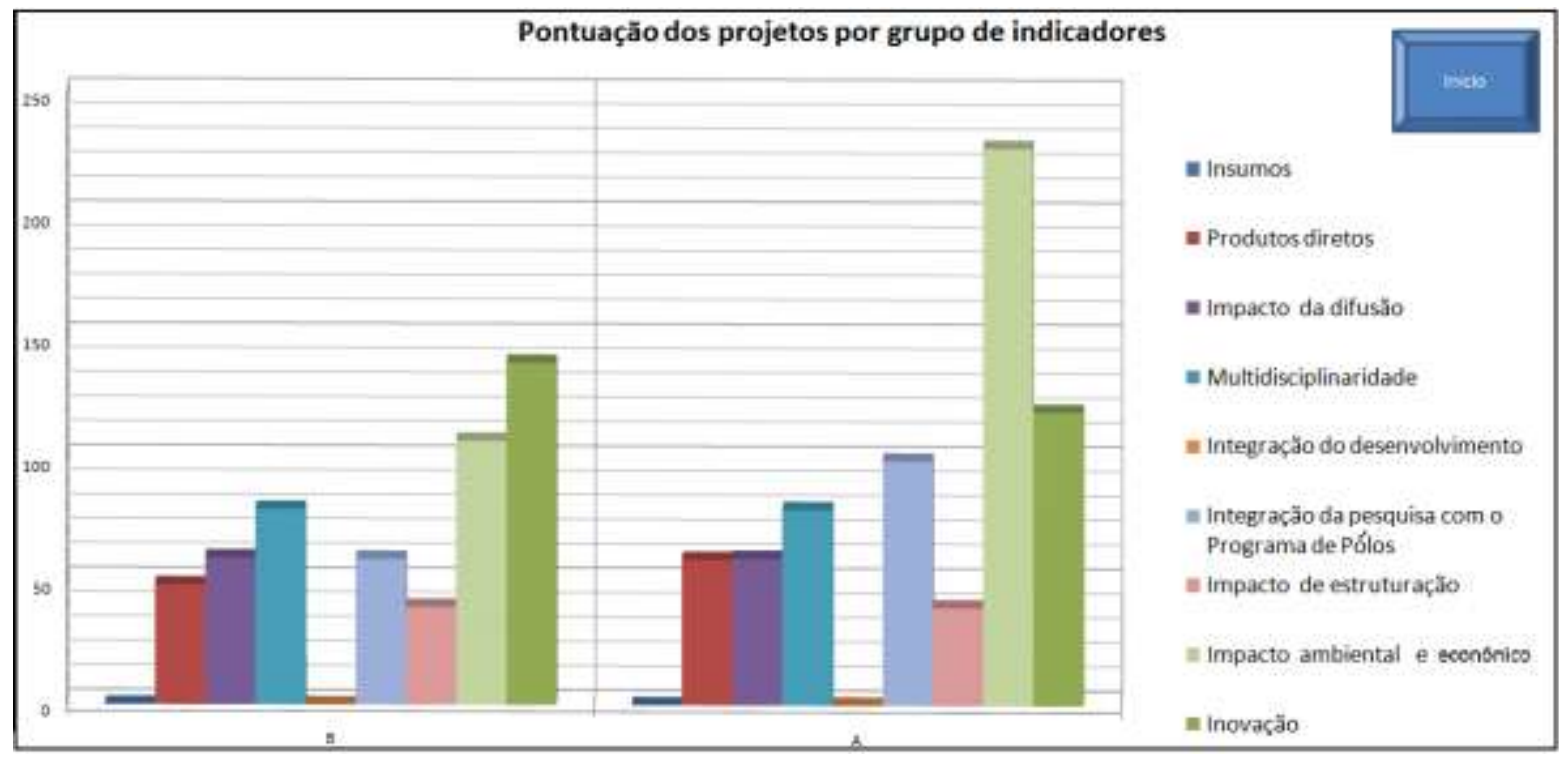

\section{CONCLUSÕES}

Este artigo apresentou os resultados de uma pesquisa exploratória que teve por finalidade desenvolver um modelo para avaliação do potencial estratégico de projetos de P\&D de inovações tecnológicas voltado ao Programa de Apoio a Polos de Inovações Tecnológicas do Estado do Rio Grande do Sul.

Foram analisados e apresentados os modelos de seleção e priorização de projetos, os Fatores Críticos de Sucesso e as diretrizes do Programa de Polos e métodos de tratamento e processamento de dados e informações.

A análise dos resultados evidenciou a efetividade do modelo proposto em subsidiar a avaliação dos pontos fortes e fracos dos projetos sob a ótica dos participantes do Programa de Polos.

Esta modelo para avaliação do potencial estratégico de projetos além de permitir a seleção e classificação de projetos de pesquisa, pode facilitar a comparação de projetos por meio de duas escalas, geral e detalhada, que mostram o valor do potencial estratégico para auxiliar em processos de tomada de decisão. 


\section{REFERÊNCIAS}

ANTONELLI, Ricardo Adriano. Conhecendo o business intelligence (BI): uma ferramenta de auxílio à tomada de decisão. Revista TECAP, v. 3, n. 3, 2009.

ASSOCIAÇÃO BRASILEIRA DE NORMAS TÉCNICAS. NBR 16001:

responsabilidade social - sistema da gestão-requisito. Rio de Janeiro: ABNT, 2004.

BARROS, Leandro A.; SILVA, Carlos E. S. da; MELLO, Carlos H. P. Identificação de fatores para a implementação de técnicas de gestão de portfólio de projetos: estudo de caso em uma empresa global do setor químico. Revista Produção Online, v.10, n.2, jun. 2010.

BELL, Judith. Projeto de pesquisa: guia para pesquisadores iniciantes em educação, saúde e ciências sociais. 4. ed. Porto Alegre: Artmed, 2008.

BEHZADIAN M. et al. A comprehensive literature review on methodologies and applications. European journal of Operational research, v. 200, n. 1, p. 198-215, 2010.

BITMAN, W. R.; SHARIF, N. A conceptual framework for ranking r\&d projects. IEEE Transactions on Engineering Management, v. 55, n. 2, p. 267-278, 2008.

BOSCARIOLI, C. Pré-processamento de dados para descoberta de conhecimento em banco de dados: uma visão geral. CONGED - CONGRESSO DE TECNOLOGIAS PARA GESTÃO DE DADOS E METADADOS DO CONE SUL, 3,. 2005. Guarapuava. Anais... Guarapuava : Unicentro, p. 101-20, 2005.

BRASIL. Lei $\mathbf{n}^{\circ}$ 10.973, de 2 de dezembro de 2004. Dispõe sobre incentivos à inovação e à pesquisa científica e tecnológica no ambiente produtivo e dá outras providências, 2004.

CAMPOS, Mansur Ferreira. Gestão de porta-fólio de projetos de p\&d em uma instituição publica de pesquisa cientifica - tecnológica em saúde: análise de um instrumento metodológico para avaliação estratégica dos projetos nas unidades de produção da FIOCRUZ". Dissertação (Mestrado na Modalidade Profissional em Saúde Publica)- Escola Nacional de Saúde Publica Sergio Arouca, 2009.

CHAO, R. O.; KAVADIAS, S. A Theoretical framework for managing the new product development portfolio: when and how to use strategic buckets. Management Science, v. 54, n. 5, p. 907-921, 2008.

COITINHO, Marcos. Influencia da incerteza no processo de decisão: priorização de projetos de melhoria. Dissertação (Mestrado em Engenharia) - Escola Politécnica da Universidade de São Paulo, São Paulo, 2007. 
COOPER, Robert G.; EDGETT, Scott G. Portfolio management for new produtcs. 2008.

CASTRO, Henrique Gonçalves de; CARVALHO, Henrique Monteiro de.:

Gerenciamento do portfólio de projetos: um estudo exploratório. Revista Gestão \& Produção, São Carlos, v.17, n.2, 2010.

DEMO, Pedro. Metodologia do conhecimento científico. 1. ed. São Paulo. Atlas, 2008.

FRANCISCO, Lourdes Terezinha dos Santos Tomé. Indicadores para avaliação de resultado de projetos de pesquisa cientifica e tecnológica. Dissertação

(Mestrado)- Programa de Pós - Graduação em Administração. Universidade Federal do Rio Grande do Sul, Porto Alegre. 2002.

HOU, Y.; WANG, B.; OUYANG, G.; SHEN, H.; HE, Y. An Analytic hierarchy process to evaluate pem fuel cell engine performance. International Journal of Hydrogen Energy, v. 36, p. 6780-6787, 2011.

HORA, Henrique Rego Monteiro da; MONTEIRO, Gina Torres Rego; ARICA Jose. Confiabilidade em questionários para qualidade: um estudo com o coeficiente alfa de cronbach. Revista Produto \& Produção, v. 11, n. 2, p. 85 - 103, jun. 2010.

JUNIOR, Euclides Reame. Fatores críticos de sucesso na gestão de projetos colaborativos de desenvolvimento de máquinas agrícolas: um estudo de caso. Dissertação. (Mestrado em Engenharia de Produção)- Escola de Engenharia de São Carlos, da Universidade de São Paulo, 2008.

JUNG, Carlos Fernando. Elaboração de projetos de pesquisa aplicados a engenharia de produção. Taquara: FACCAT, 2010. Disponível em: <http://www.metodologia.net.br>. Acesso em: 27 jan. 2010.

JUNG, Carlos F. Metodologia científica e tecnológica. 2. ed. Taquara, 2009. Disponível em: <http://www.metodologia.net.br>. Acesso em: 29 nov. 2009a.

JUNG, C. F. et al. Fatores que impactam o desempenho de um programa estadual de inovação tecnológica sob o enfoque Macroergonômico. Revista Espacios (Caracas), v. 30, p. 19-21, 2009b.

JUNG, C. F. et al. Uma proposta de modelo comunitário para pesquisa e desenvolvimento (P\&D). CONGRESSO DA ASSOCIAÇÃO BRASILEIRA DAS INSTITUIÇÕES DE PESQUISAS TECNOLÓGICAS, 5,. 2008. Anais... -ABIPTI, 2008a.

JUNG, C. F. ; RIBEIRO, J. L. D. ; CATEN, C. S. T. . Análise de um modelo para pesquisa e desenvolvimento de inovações tecnológicas voltado ao desenvolvimento regional. Revista Innovare, v. 6, p. 11-33, 2008b. 
KLEINSMANN, M.; VALKENBURG, R. Learning from collaborative new product development projects. Journal of Workplace Learning, v. 17, n. 3, p. 146156, 2005.

LÖBLER, Mauri Leodir; BOBSIN, Débora; VISENTINI, Monize Sâmara. Alinhamento entre o plano de negocio e o plano de tecnologia de informação das empresas: análise comparativa através dos níveis de maturidade e fatores críticos de sucesso. Revista de Gestão da Tecnologia e Sistemas de Informação, v. 5, n. 1, p.37-60. 2008.

LYRA, Gabriela Marques; CALADO, Lara; ALMEIDA, Adiel Teixeira de. Modelo de precisão multicritério para priorização de sistemas de informação. Recife: Universidade Federal de Pernambuco, 1999.

MACEDO, Dayana Carla de; MATOS, Simone Nasser. Extração de conhecimento através da mineração de dados. Revista de Engenharia e Tecnologia, v.2, n.2, 2010.

MAGALHÃES, Ivan Luizio R.G. Balanced Scorecard como ferramenta de seleção de projetos de TI - Desmistificando a "Sacred Cow". SEMINÁRIO GESTÃO DE PROJETOS. SECEPE. São Paulo, Anais... São Paulo, 2003.

MELLO, Sofia Aragão Palha de et al. Modelo de Priorização de projetos e atividades em ambientes de múltiplos projetos. ENEGEP, 26,. 2006. Fortaleza. Anais.... Fortaleza, 2006.

MORAIS, Roberto Tadeu Ramos. Planejamento estratégico: um bem ou mal necessário?. 2. ed. Rio de Janeiro: Fundo de Cultura, 2005.

OCDE. GABINETE ESTATÍSTICO DAS COMUNIDADES EUROPÉIAS, Manual de Oslo: diretrizes para coletas e interpretação de dados sobre inovação. 3 ed. FINEP, 2007a.

. GABINETE ESTATÍSTICO DAS COMUNIDADES EUROPÉIAS, Manual de Frascati: proposta de práticas exemplares para inquéritos sobre investigação e desenvolvimento experimental. Coimbra: Impressão G.C. Ltda, 2007b.

PAULA, Fabio F. P.; AMARAL, Daniel C.; ROZENFELD, Henrique. Análise da integração entre um sistemas de integração de dados de documentos e um sistema de gestão de projetos contexto da gestão do ciclo de vida de produtos (PLM).

Revista Produção Online. Ed. Especial, dez. 2007.

PADOVANI, Marisa; CARVALHO, Marly Monteiro de; MUSCAT, Antonio Rafael Namur. Seleção e alocação de recursos em portfólio de projetos: estudo de caso no setor químico. Revista Gestão \& Produção. São Carlos, v.17, n.1, p. 157-180, 2010. 
PEGORARO, Camila; SAURIN, Tarcísio Abreu; PAULA. Istefani Carísio de. O papel da gestão de requisitos de projetos em ambientes construídos: um estudo de caso. Revista Produção Online. Florianópolis, SC, v.11, n. 4, p. 965-994, out./dez. 2011.

PENTEADO, Fernanda Bessani Leite. Método de filtragem Fuzzy para avaliação de bases de dados. Dissertação (Mestrado em Engenharia Elétrica)- Escola de Engenharia de São Carlos, da Universidade de São Paulo, 2009.

PEREIRA, Danilo F.; BICHI, Camila A.; FILHO, Luís R. Gabriel; GABRIEL,Camila P.C. Sistema fuzzy para estimativa do bem - estar de matrizes pesadas. Eng. Agríc. [online], v.28, n.4, p. 624-633, 2008.

PMI - PROJECT MANAGEMENT INSTITUTE. Um guia de conjuntos em gerenciamento de projetos. 4. ed. Pennsylvania: PMI, 2008.

QUEIROZ, Odilon Vanni de et al. A construção da base nacional de dados em terapia renal substitutiva (TRS) centrada no individuo: relacionamento dos registros de óbitos pelo subsistema de autorização de procedimento de alta complexibilidade (Apac/SIA/SUS) e pelo sistema de informação sobre mortalidade (SIM) - Brasil, 2000-2004. Epidemiol. Serv. Saúde, p. 107-120, 2009.

RAMOS, Marcelo da Silva. Utilização da abordagem multicritério para priorização do portfólio de projetos de investimento. Dissertação (Mestrado)Programa de Pós - Graduação e pesquisa em Administração e Economia. Faculdades de Economia e Finanças IBMEC, Rio de Janeiro, 2010.

RIO GRANDE DO SUL. Lei n 11.179, de 25 de junho de 1998. Dispõe sobre a consulta direta à população quanto à destinação de parcela do Orçamento do Estado do Rio Grande do Sul voltada a investimentos de interesse regional.1998.

ROCHA, Fábio Moutinho et al. Gerenciamento de portfólio: proposta de um modelo adaptado ao terceiro setor. SIMPEP, 16,. 2009. Bauru. Anais... Bauru, 2009.

ROZENFELD, Henrique; et al. Gestão de desenvolvimento de produtos: uma referência para a melhoria do processo. São Paulo: Saraiva, 2006.

SANTORO, Rodrigo Cesar. Modelo para implantação de sistema de indicadores estratégicos, visando à sustentabilidade empresarial. Monografia (Graduação em Engenharia de Produção)- Escola Politécnica da Universidade de São Paulo. São Paulo, 2003.

SANTOS, Luiz Alberto Cardoso dos et al. Controle de programa de p\&d em uma universidade através da gestão de portfólio. ENEGEP, 27, . 2007. Foz do Iguaçu. Anais... Foz do Iguaçu, 2007. 
SANTOS, Roberto Ângelo Fernandes. Metodologia e uso de técnicas de exploração e análise de dados na construção de data warehouse. 2002. Dissertação (Mestrado)- Pós - Graduação em Ciências da Computação. Universidade Federal de Pernambuco, Recife, 2002.

SCT. Secretaria Ciências e Tecnologia. Pagina de introdução. Disponível em: <http://www.sct.rs.gov.br/index2.php\# include/mostra_apresentacao.php?>. Acesso em: 27 jan. 2010a.

Secretaria Ciências e Tecnologia. Disponível em: < http://www5.sct.rs.gov.b r/polos>. Acesso em: 03 out. 2010b.

Programa pró-inovação resolução normativa n 01/2010. Disponível em: <http://www.sct.rs.gov.br/include/download.php?arq=1276773664PR O_INOVACAO_Resolucao_Normativa_sobre_CARTA_CONSULTA_17_06_10.doc> Acesso em:22 jul. 2010c.

Termo de referencia para apresentação de projetos $n \circ 001 / 2009$.

Disponível em: <http://www5.sct.rs.gov.br/polos/projeto/referencia/2_cham ada.pdf >. Acesso em: 05 jul. 2010d.

Termo de referencia para apresentação de projetos n॰ 001/2008.

Disponível em: <http://sucuri.cpd.ufsm.br/noticias/files/arq/18278.pdf>. Acesso em: 05 jul. 2010e.

SILVA, Samuel de Assis; LIMA, Julião Soares de Souza. Lógica de fuzzy no mapeamento de variáveis indicadoras de fertilidade do solo. IDESIA, Chile, v. 27, n. 3, p. 41-46, dez. 2009.

SILVA, Fábio G.; HARTMAN, Adriane; REIS, Dalcio R. Avaliação do nível de inovação tecnológica nas organizações: desenvolvimento e teste de uma metodologia. Revista Produção Online, v. 8, n. 4, 2008.

SOUZA, Alexandre; PROCILE, Gabriel. Aplicação da lógica de fuzzy em processos de decisão econômica. ANPEC SUL. Anais... Maringá, 2009.

SUZUKI, Érika. Uma abordagem de engenharia do conhecimento à gestão estratégica da inovação. Dissertação (Mestrado)- Programa de Pós-Graduação em Engenharia de Produção e Gestão do conhecimento. Universidade Federal de Santa Catarina, 2008.

THEVENOT, H. J. et al. A multiattribute utility theory: based approach to product line consolidation and selection. INTERNATIONAL DESIGN ENGINEERING AND TECHNICAL CONFERENCE \& COMPUTER AND INFORMATION ENGINEERING CONFERENCE Anais..., Sep 10-13, 2006, Philadelphia, Pennsylvania, USA. 
TRZECIAK, Dorzeli S. et al. Modelagem da Informação: uma abordagem voltada à integração de dados. Revista Alcance, São José, Santa Catarina, 2003.

TRKMAN, $P$. The critical success factors of business process management.

International Journal of Information Management, v. 30, n. 2, p. 125-134, 2010.

VARGAS, Marco Antônio; FILHO, Nery dos Santos; ALIEVI, Rejane Maria. Sistema gaúcho de inovação: considerações preliminares e avaliação de arranjos locais selecionados. Rio de Janeiro: Nova técnica, 1998.

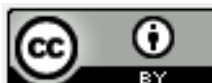

Artigo recebido em 19/08/2012 e aceito para publicação em 19/04/2013. 